
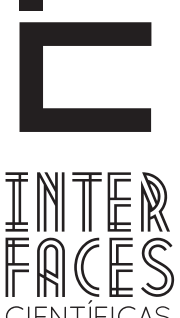

CIENTÍFICAS

HUMANASE SOCIAIS

ISSN IMPRESSO 2316-3348

E-ISSN 2316-3801

DOI - 10.17564/2316-3801.2019v7n3p81-92

\title{
POSSIBILIDADES E LIMITES DA UTILIZAÇÃO DO FACEBOOK COMO UMA FERRAMENTA DE CONSTRUÇ̧̃̃O DE DIÁLOGOS E SABERES ENTRE MULHERES
}

\author{
POSSIBILTIES AND LIMITS OF THE USE OF FACEBOOK AS A TOOLFOR THE CONSTRUCTION OF DIALOGUES AND KNOWLEDGE BETWEEN WOMEN \\ POSIBILIDADESYLÍMITES DELAUTILIZACIÓN DEL FACEBOOKCOMO UNAHERRAMIENTA DECONSTRUCCIÓN DEDIÁLOGOSYSABERESENTREMUJERES
}

Winnie Bueno ${ }^{1}$

Joanna Burigo ${ }^{2}$

\section{RESUMO}

A democratização do acesso à internet possibilitou aos movimentos sociais uma nova forma de articulação. Nesse sentido, as ativistas dos movimentos de mulheres encontraram no uso do Facebook, uma outra possibilidade de fomentar as bases necessárias para o crescimento do conhecimento individual e coletivo. Assim, partindo de uma visão não essencialista, buscamos neste artigo compreender se a utilização das ferramentas comunicativas disponíveis no Facebook auxilia na compreensão de linguagens distintas e estratégias de resistência na luta pelo combate ao sexismo e racismo. A partir de uma metodologia que privilegia as vivências das autoras, analisamos as formas com que as mulheres negras e não-negras formulam saberes e diálogos catalisadores de mobilizações que se pautem de forma não-hierarquizada. Utilizamos nessa análise perspectivas do feminismo negro que discorrem sobre o papel do feminismo na emancipação de mulheres subalternas.

\section{PALAVRAS-CHAVE}

Ciberativismo. Feminismo. Feminismo negro. 


\section{ABSTRACT}

The democratization of access to the internet has made possible for social movements to articulate their demands and actions in new ways. In this sense many activists from various feminist and women's movements found, in the uses of Facebook, another possibility to foster the necessary bases for the growth of individual and collective knowledges. Thus, based on a non-essentialist view, we seek in this article to understand if the use made of communicative tools available from Facebook are of assistance for the understanding of the many distinct languages and strategies of resistance against sexism and racism. Based on a

\section{RESUMEN}

La democratización de acceso a la Internet ha proporcionado a los movimientos sociales una nueva manera de articularse. Además, muchas activistas de movimientos femeninos se hallaron en la utilización de Facebook, otra posibilidad de fomentar las bases para el crecimiento de los individuos y los conocimientos técnicos. En el caso, buscase descubrir se las herramientas comunicativas disponibles en Facebook ayudan a comprensión de las distintas lenguas y las estrategias de resistencia contra el sexismo y el racismo. A partir de una metodología que privilegia las vivencias de las methodology that privileges the experiences of the authors, we analyze whether black and non-black women formulate knowledge and dialogues to catalyze mobilizations that take place in non-hierarchical ways. To substantiate our analysis we have employed black feminist perspectives who discuss the role of feminism in the emancipation of subaltern women.

\section{KEYWORDS}

Cyberativism. Feminism. Black Feminism autoras, analizamos las formas con que las mujeres negras y no negras formulan saberes y diálogos catalizadores de movilizaciones que se establecen de forma no jerarquizada. Utilizamos en este análisis perspectivas del feminismo negro que discurren sobre el papel del feminismo en la emancipación de mujeres subalternas.

\section{PALABRAs CLAVE}

Ciberactivismo. Feminismo. Feminismo Negro. 


\section{INTRODUÇ̄̃̃O}

A formulação desse artigo se deu a partir da observação das interações entre mulheres negras e não negras que participam de dois grupos hospedados na rede social Facebook: Feminismo e a política inter/ nacional - vinculado à \#CDMJ e Casa Da Mãe Joanna DIÁLOGOS. Ambas iniciativas são coordenadas pela ativista social Joanna Burigo e têm por objetivo fomentar debates pertinentes às questões de gênero, classe, raça e política, alinhadas a escopos teóricos dos feminismos de maneira dialógica e participativa.

A composição destes grupos, que integram mulheres, homens e pessoas trans, negras e não negras, enseja uma análise sobre as possibilidades de formulação de agendas feministas que possam se estabelecer a partir da constituição de redes em que a diversidade do tecido social brasileiro não seja um impeditivo para a atuação conjunta de mulheres (CARVALHO, 2017, p. 348).

0 crescimento da participação da sociedade brasileira no acesso à internet provocou mudanças nas formas com que os movimentos feministas organizam suas reivindicações. Se antes do incremento da tecnologia a principal forma de veiculação das pautas das mulheres eram formuladas no interior dos sindicatos, partidos políticos e grupos auto organizados que se reuniam presencialmente e debatiam suas demandas e estratégias de mobilização, hoje parte significativa da articulação feminista se dá no meio virtual. Há uma nova forma de fazer feminismo e o ativismo está intensamente "conectado" às ferramentas fornecidas pela rede mundial de computadores.

Entre essas ferramentas, a maioria pensadas e projetadas por homens brancos, uma que merece destaque é o Facebook pela multiplicidade de formas de interação que se dão basicamente por meio dos comentários em postagens a partir de páginas de coletivos e ativistas, mobilizações por hashtags e textos publicados em perfis pessoais. A luta por emancipação feminina, a pauta universal do feminismo, ganhou novos contornos, que se estabelecem dentro das redes sociais.

Para analisar o potencial dessas ferramentas discursivas, iremos utilizar escopos teóricos do pensa- mento político de mulheres negras a partir de uma visão intersecional de análise da sociedade, compreendendo os efeitos das "discriminações interativas" (CRENSHAW, 2002, p.171) nas experiências e vivências das mulheres. Escolhemos essa metodologia, porque reconhecemos que o sistemático apagamento da produção intelectual das mulheres negras no cânone acadêmico enseja formulações que estejam consubstanciadas por arcabouços teóricos capazes de visibilizar a organização do pensamento feminista negro. Nossa percepção é a de que os novos estudos sobre feminismos necessitam reconhecer esse histórico de apagamento e subverte-lo por meio da centralização das epistemologias feministas negras (COLLINS, 2002, p. 256).

Por mais que o Facebook tenha sido projetado a partir de homens brancos, estudantes da Ivy League e pertencentes às classes dominantes, essa ferramenta tem possibilitado a articulação de mulheres subalternas tanto a partir da possibilidade de vocalização das suas experiências, quanto por meio de mobilizações que ocorrem dentro e fora dessa rede. Além disso, nossa hipótese é de que as redes sociais possibilitam o compartilhamento de trajetórias e perspectivas distintas que podem encontrar pontos de convergência que fortalecem as lutas feministas.

O Facebook, ao ser pano de fundo, de mobilizações e debates que denunciam as lógicas opressoras do capitalismo, principalmente por meio das vocalizações encontradas no ativismo das mulheres negras, tem sido de fato apropriado pelas vozes historicamente ignoradas e silenciadas? As redes de partilha entre mulheres com vivências distintas são facilitadas por meio das redes sociais? Há uma efetiva troca de saberes nos diálogos estabelecidos no Facebook? Todas esses questionamentos estão no interior da formulação deste trabalho, não pretendemos esgotar as possibilidades de respostas para os mesmos, na verdade o que se estabelece como intenção desse escrito é levantar essas inúmeras perguntas como mobilizadoras de reflexões sobre os feminismos e suas articulações cibernéticas, assim como promover um questionamento a respeito das maneiras com que se dão as in- 
terações entre mulheres brancas e negras na veiculação das pautas do feminismo brasileiro.

\section{RACISMO, INTERSECCIONALIDADE E POSSIBILIDADES DEDIÁLOGOSA PARTIR DASREDES}

0 anseio pelo combate às desigualdades que enfrentam as mulheres em todo mundo é uma característica que está inserida em todos os feminismos, estando também mobilizada nas formas com que as ativistas feministas e os movimentos de mulheres têm organizado suas pautas no Facebook. Contudo, nem sempre a perspectiva da interseccionalidade está presente nessas organizações, havendo constantemente conflitos entre mulheres negras e não negras que se estabelecem a partir de uma aparente ausência (ou falha nos processos) de alteridade e empatia nas configurações dos feminismos, especialmente aqueles que não são protagonizados por mulheres negras.

O conceito de interseccionalidade passou ao cânone acadêmico a partir dos escritos de Kimberlé Crenshaw, fundadora do movimento intelectual Critical Race Theory, professora da UCLA e da Columbia Law School. Sinteticamente, o conceito de interseccionalidade pode ser descrito da seguinte forma:

\begin{abstract}
A interseccionalidade é uma conceituação do problema que busca capturar as consequências estruturais e dinâmicas da interação entre dois ou mais eixos da subordinação. Ela trata especificamente da forma pela qual o racismo, o patriarcalismo, a opressão de classe e outros sistemas discriminatórios criam desigualdades básicas que estruturam as posições relativas de mulheres, raças, etnias, classes e outras. Além disso, a interseccionalidade trata da forma como ações e políticas específicas geram opressões que fluem ao longo de tais eixos, constituindo aspectos dinâmicos ou ativos do desempoderamento. (CRENSHAW, 2002, p. 178).
\end{abstract}

É a partir das interpretações que as feministas negras brasileiras fazem da importância desse conceito no enfrentamento das discriminações múltiplas ou aprofundadas, que surge o chamado feminismo interseccional, que passa a figurar como uma vertente do feminismo brasileiro nos últimos anos. Ou seja, a perspectiva teórica de Crenshaw (2002), uma ferramenta de análise social, nomeou um feminismo que se pauta pela percepção de que mulheres irão experimentar as opressões de forma diferentes e que, as intersecções entre raça, classe e gênero não podem ser afastadas da prática feminista. $\mathrm{O}$ ativismo interseccional, portanto, considera em suas análises esses três fatores para consubstanciar suas formulações, pautas e ações. Ao menos em teoria, esse é o escopo que fundamenta o ativismo do feminismo interseccional.

A solidificação do feminismo interseccional no Brasil se dá principalmente por meio das redes, em movimentos liderados por ativistas que utilizam as ferramentas da internet como principal forma de expansão das suas ideias. Blogs e sites como Blogueiras Feministas, Blogueiras Negras, Capitolina e grupos do Facebook são alguns dos locais de organização da interseccionalidade enquanto vertente no Brasil. No que pese a importância dessas formas de veiculação da interseccionalidade enquanto uma característica de um tipo de feminismo, essa percepção de uma nova configuração para o feminismo tem sido fomentada pelo ativismo intelectual negro internacional a pelo menos 40 anos.

O conceito organizado academicamente por Kimberlé Crenshaw (1994) no final da década de 1980 já vinha sendo utilizado nas articulações ativistas de feministas negras, como é o caso de Audre Lorde (1984), Bell Hooks (1981) e Lélia Gonzales (1983). O chamado dessas mulheres era pelo reconhecimento de que a teoria feminista estabelecida até então ignorava questões de raça e sexualidade. Em outras palavras, um chamado para o reconhecimento da preponderância de racismo e lesbofobia dentro do próprio feminismo.

É uma arrogância peculiar da academia promover qualquer discussão sobre teoria feminista sem considerar nossas muitas diferenças, e sem considerar as contribuições de mulheres pobres, mulheres negras, mulheres terceiro-mundistas e mulheres lésbicas. $E$, mesmo assim, estou aqui enquanto feminista negra lésbica, convidada para comentar o único painel em que as contribuições das feministas negras e lésbicas serão apresentadas. 0 que isso diz a respeito da 
perspectiva desta conferência é triste, num país onde racismo, sexismo e homofobia são inseparáveis. Ler essa programação é assumir que lésbicas e mulheres negras não tem nada a dizer sobre existencialismo, o erótico, a cultura e o silêncio das mulheres, o desenvolvimento da teoria feminista, ou sobre heterossexualidade e poder. E o que significa, em termos políticos e pessoais, quando mesmo as duas mulheres negras que estão aqui presentes foram literalmente encontradas na última hora? 0 que significa quando as ferramentas de um patriarcado racista são utilizadas para examinar os frutos deste mesmo patriarcado? Significa que apenas os perímetros mais estreitos de mudança são possíveis e aceitáveis. (LORDE, 1984, p. 110, tradução nossa).

Passados mais de 40 anos desse discurso de Audre Lorde, proferido em uma conferência comemorativa do aniversário de 30 anos da obra O Segundo Sexo, de Simone de Beauvoir, ativistas negras ainda chamam a atenção do feminismo padrão para os silenciamentos, invisibilidades e ignorâncias acerca das experiências e contribuições das mulheres negras ao feminismo. Essas reivindicações são perceptíveis no ciberativismo e são cada vez mais potentes. A percepção das mulheres negras enquanto sujeitas de suas próprias histórias e trajetórias tem proporcionado o fortalecimento do feminismo negro no último período.

Esse movimento, esta circunscrito na necessidade da população negra formular definições próprias sobre suas identidades, trajetórias, vivências e demandas, ou seja, a construção de um "pensamento político negro" (COLLINS, 2002), gestado a partir da

[...] reelaboração da representação do negro/a, a construção de um discurso próprio sobre a sua condição racializada numa perspectiva multidisciplinar, ou seja, do ponto de vista político, social, cultural e estético e a relação desses universos com o restante da sociedade não-negra. (BARRETO, 2005, p. 15).

O fortalecimento desse pensamento político negro, e no caso que analisamos nesta pesquisa especialmente da organização do pensamento político de mulheres negras, tem gerado reações diversas na população branca. As interações da branquitude nesse aspecto se dão em duas perspectivas, uma localiza- da a partir da branquitude crítica, outra por meio da ofensiva da branquitude acrítica .

A noção de branquitude crítica que articulamos neste trabalho está em conformidade com o disposto pelo historiador e doutor em sociologia Lourenço Cardoso (2010). Em suas pesquisas, Cardoso localiza o surgimento do conceito de branquitude a partir dos estudos percursores de Du Bois (1935), que para o autor foi o primeiro intelectual a propor uma problematização a respeito da identidade branca, seguido por Fanon (1952) que articulou em Pele Negra, mascaras brancas conceitos centrais para compreender as interações sociais entre negros e brancos nas sociedades marcadas pelas lógicas do colonialismo.

Para Cardoso, a noção de branquitude crítica diz respeito à reprovação pública do racismo, no que pese essa reprovação pública não necessariamente dizer respeito a um engajamento efetivo de combate ao racismo. Conforme o autor, essa reprovação nem sempre vai ser ratificada no privado, principalmente no que tange as questões referentes ao racismo no Brasil, Cardoso ainda invoca o pensamento de Florestan Fernandes para elucidar que o brasileiro tem extremas limitações em admitir a existência do racismo (CARDOSO, 2010, p. 611-612).

Essa resistência foi encontrada em muitos diálogos que observamos nos grupos analisados, mesmo que as pessoas brancas inseridas nos debates que organizavam-se a partir de conflitos ou narrativas centradas na questão racial indicassem percepções que apontavam para um repúdio a respeito do racismo, a exposição das ideias dessas pessoas apontava para uma dificuldade em reconhecer o sistema de privilégios nas quais elas estavam inseridas por serem brancas, ademais é bastante perceptível nos diálogos e trocas estabelecidos que ocorre uma tentativa sistemática de reduzir os impactos do racismo na estrutura de classes.

Contudo, há também engajamentos das mulheres brancas nessas situações que revelam uma condenação por parte das mulheres brancas do racismo e de suas práticas de forma mais contundente, organizada inclusive a partir de marcos teóricos do pensamento político negro. 
Um exemplo que ilustra essa questão é a recepção de mulheres negras e mulheres brancas à narrativa de Thuane Cardoso que relatou em seu perfil social na rede Facebook que teria sido interpelada por mulheres negras devido ao uso de um turbante. 0 relato de Thuane gerou uma mobilização via hashtags, prática bastante utilizada pelos movimentos feministas para repercutir assuntos relevantes para as demandas das mulheres. A mídia também publicitou o fato que gerou intensos debates nas redes sociais que se centralizavam nas questões da existência ou não de apropriação cultural quando do uso de turbantes por pessoas brancas.

Não iremos nos deter aqui sobre as implicações teóricas a respeito da apropriação cultural porque não é o escopo desse trabalho. A perspectiva é tentar localizar as interações que se dão entre as mulheres negras e as mulheres brancas a partir de suas experiências e vivências, centralizando na existência ou não do reconhecimento acerca das consequências das discriminações múltiplas no fortalecimento do patriarcado, bem como a importância dessa percepção para um efetivo combate ao sexismo. Uma vez que:

O lugar em que nos situamos determinará nossa interpretação sobre o duplo fenômeno do racismo e do sexismo. Para nós o racismo se constitui como a sintomática que caracteriza a neurose cultural brasileira. Nesse sentido, veremos que sua articulação com o sexismo produz efeitos violentos sobre a mulher negra em particular. (GONZALES, 1983, p. 224).

0 debate a respeito da situação narrada por Thuane iniciou a partir do questionamento de uma participante branca do grupo sobre o tema da apropriação cultural. A postagem surgiu acompanhada da notícia sobre o caso veiculada no site HuffPostBrasil , na interpelação a participante solicita opiniões do grupo, principalmente de pessoas negras. A postagem gerou 88 comentários e no que pese a interlocutora ter solicitado "a opinião das negras do grupo, principalmente" os primeiros comentários a surgir foram de mulheres brancas. Os comentários das mulheres brancas variam, basicamente, entre endossar a res- posta de Thauane, admitir a existência de racismo, mas minorar o impacto da estrutura racista no caso e repudiar a resposta de Thuane. Os comentários das mulheres negras apontam para a invisibilização das opiniões dessas sobre a temática, questionam o "lugar de fala", visibilizam que há muitas mulheres brancas comentando no que pese a solicitação da autora da postagem, bem como relatam situações de racismo vivenciadas em razão do uso do turbante. É interessante notar que muitas interlocutoras brancas escrevem sobre a necessidade de escuta, "revisão de privilégios", bem como compartilham textos de mulheres negras sobre apropriação cultural e racismo. Há uma percepção de uma solicitação explícita por parte das mulheres brancas em relação às mulheres negras que aponta para uma reivindicação de compreensão da linguagem do opressor por parte do oprimido, no que pese mulheres brancas terem dificuldades de se perceberem como opressoras, conforme Audre Lorde (1980, p.144):

\begin{abstract}
Tradicionalmente, na sociedade estadunidense, é de membros de grupos oprimidos e objetificados que se espera mãos estendidas e a feitura de pontes entre as realidades de nossas vidas e a consciência de nossos opressores. Pois, para sobreviver, aqueles de nós para quem a opressão é tão americana como a torta de maçã, sempre tivemos que ser observadores para nos familiarizarmos com as linguagens e modos do opressor, às vezes adotando-as para termos alguma ilusão de proteção. Em outras palavras, é responsabilidade dos oprimidos ensinar aos opressores seus erros. (Tradução nossa).
\end{abstract}

Há, portanto, uma percepção parte da branquitude crítica de que a responsabilidade por apresentar as nuances do racismo é das pessoas negras. 0 que percebemos é que a própria forma com que o diálogo sobre o episódio analisado foi proposto evidencia essa formulação de Audre Lorde, a interlocutora branca solicita a opinião das mulheres negras para que elas sejam responsáveis pelo processo de desconstrução do ideário racista impregnado na formação da consciência das mulheres brancas. Não há uma responsabilidade genuína em desconstruir a opressão, mas sim a 
manutenção de uma localização em que se ignora os próprios atos racistas e se pede para aqueles que são vitimados pelo menos que apontem a violência sistêmica a que estão submetidos.

Outra questão relevante que foi possível perceber a partir da observação desse episódio é a maneira com que as mulheres brancas automaticamente prestaram solidariedade a narrativa de Thauane, uma característica marcante da branquitude observada pela pesquisadora Maria Aparecida Bento, debates sobre o racismo que envolvem a branquitude crítica são marcados por uma perspectiva em que muito raramente 0 branco coloca a si enquanto opressor.

Os sujeitos brancos imbricados nesses debates desejam discutir o racismo em uma localização em que os mesmos não estejam visibilizados enquanto pessoas que acessam os privilégios do sistema racista. "Ao discutir sobre racismo, elas esperam abordar uma opressão que 'está lá' na sociedade, e não em algo que as envolva diretamente, ou que envolva a instituição da qual fazem parte" (BENTO, 2002, p. 148).

Por fim, cabe destacar que não ignoramos nessa observação que o ponto de vista de mulheres negras e mulheres brancas é distinto (COLLINS, 2003). A localização de mulheres negras e mulheres brancas dentro da estrutura hierárquica de poder é inegavelmente diferenciada e hierarquizada, essa distinção se dá por uma razão racial. No que pese a inexistência de raças enquanto conceito biológico, a organização social de raça ainda está em voga na estrutura capitalista. As distinções socioeconômicas no Brasil, portanto, organizam-se a partir do racismo e os privilégios oriundos dessa organização também se dão dentro de uma hierarquia racial, onde ser branco significa estar mais próximo das estruturas do poder. Essa proximidade do poder do branco e esse distanciamento do poder do negro, faz com que as análises organizadas por cada um desses grupos se mobilizem a partir de lugares distintos.

Debates que envolvam as questões raciais frequentemente são relativizados a partir de chavões ou questionamentos que se localizam dentro da lógica do mito da democracia racial brasileira. No caso que analisamos, os sucessivos relatos de mulheres negras que foram discriminadas por usarem turbantes, relacionando esse uso à sujeira, "macumbaria", ou outros estereótipos que desumanizam as mulheres negras e impossibilitam que as mesmas sejam responsáveis pela própria definição enquanto sujeito, demonstram a tentativa de uma agência política por parte dessas mulheres que atente para a realidade das sutilezas do racismo que frequentemente é negada pela branquitude, a qual aparece motivada por uma antiescuta, ou seja, uma escuta que não é engajada. Ainda,

\begin{abstract}
Essa negação, frequentemente aparece quando não queremos enfrentar uma dada realidade, quer porque não desejamos nos ver como sujeitos de determinados tipos de ações, quer porque temos interesses nem sempre confessáveis em jogo, ou ainda porque aceitar a realidade do racismo, significa ter que realizar mudanças. Mudar por exemplo, no sentido de reconhecer que muitas vezes aquilo que orgulhosamente classificamos como mérito, está na verdade marcado também pelo privilégio, ou seja, numa sociedade racializada, ser branco sempre faz diferença. Dito de outra maneira, negros nas mesmas condições que brancos, não costumam ter as mesmas oportunidades, os mesmos tratamentos. (BENTO, 2002, p. 148).
\end{abstract}

Mesmo havendo uma aderência bastante forte entre as participantes dos grupos analisados da perspectiva interseccional do feminismo, nos debates analisados há frequentemente uma ausência da mobilização desse conceito nas interações. 0 debate das questões raciais é eclipsado por uma evidência de uma visão padrão do feminismo que ignora os aprofundamentos do sexismo relacionado com o racismo. Existem questionamentos de mulheres brancas nesses debates que indicam uma preocupação com "os rumos do feminismo" uma vez que mulheres negras estariam cerceando a liberdade dos corpos de mulheres brancas ao dizer o que elas podem ou não vestir. Esse tipo de discurso se dá na lógica já articulada anteriormente em que a branquitude crítica minimiza seus próprios privilégios simbólicos ao estabelecer diálogos que se encontram na esfera das questões relacionadas ao racismo. 
Os privilégios que resultam do pertencimento a um grupo opressor é um dos conflitos a serem enfrentados, particularmente, pelos brancos antirracistas. Esse conflito pessoal tende a emergir no momento em que se visibiliza a identidade racial branca. Desta forma, a branquitude crítica segue mais um passo em direção à reconstrução de sua identidade racial com vistas à abolição do seu traço racista, mesmo que seja involuntário, mesmo que seja enquanto grupo. A primeira tarefa talvez seja uma dedicação individual cotidiana e, depois, a insistência na crítica e autocrítica quanto aos privilégios do próprio grupo. (CARDOSO, 2010, p. 624).

A premissa de sujeitar as pessoas negras num lugar de raiva, emoção, e colocar a si mesmo no lugar da razão e da parcimônia é uma estratégia que está consubstanciada na manutenção do status quo. Ao mesmo tempo, parte das mulheres brancas que dialogaram no episódio que analisamos articulam posições que revelam o questionamento da estrutura de privilégios racista, apontando um certo enfrentamento dos conflitos subjetivos que implicam nessa percepção de si mesma como opressora. A perspectiva interseccional, nesse sentido, nos parece ser uma saída para organizar os diálogos que se dão nas redes feministas a partir de uma localização menos narcísica, onde as mulheres brancas sejam capazes de mobilizar suas críticas ao racismo não apenas num lugar de autopercepção, mas como uma estratégia de redefinição da sociedade.

A construção de redes, cibernéticas ou não, que possibilitem uma assimilação genuína dada contribuição das experiências das mulheres negras da diáspora na construção de uma agenda política coletiva de combate ao sexismo e ao racismo, tem potencial de ocorrer a partir das redes sociais. Para tanto, contudo, é necessário que o compartilhamento das vivências e experiências das mulheres negras não sejam diminuídas ou silenciadas em razão do silêncio e da anuência das mulheres brancas sobre as consequências do racismo nas suas próprias vidas.

O silêncio, a omissão ou a distorção que há em torno do lugar que o branco ocupou e ocupa, de fato, nas relações raciais brasileiras. A falta de reflexão sobre o papel do branco nas desigualdades raciais é uma forma de reiterar persistentemente que as desigualdades raciais no Brasil constituem um problema exclusivamente do negro, pois só ele é estudado, dissecado, problematizado. (BENTO, 2012, p. 26).

No que pese a dificuldade desse exercício de reconhecimento das diferenças entre mulheres negras e não negras, e seus impactos na perspectiva da interseccionalidade, mulheres negras têm constituído redes transnacionais importantes ainda que presentes as diferenças de nacionalidade entre elas. Esse engajamento se dá a partir do momento em que as mulheres negras tomam consciência da importância de serem portadores de suas próprias vozes e da concepção a respeito de si (COLLINS, 1986).

O espaço de formulação de uma agenda feminista negra internacional, em que as considerações das mulheres terceiro-mundistas fossem contempladas de maneira equitativa com as perspectivas das mulheres negras do norte global, se deu a partir da participação das primeiras em conferências, encontros, seminários e eventos internacionais, como o III Encuentro de Mujeres Afrodescendientes (III Encontro de Mulheres Afrodescendentes) e III Conferência das Nações Unidas contra o Racismo e Xenofobia. Assim, mulheres negras ultrapassaram fronteiras geográficas para articular resistências contra o racismo, o sexismo, o apagamento e o silenciamento experienciados tanto no feminismo quanto no movimento negro (PERRY, 2009 , p. 6). Ativistas negras organizadas a partir de uma perspectiva diaspórica. O conceito de diáspora africana que utilizamos aqui é o proposto por Luiza Bairros, qual seja:

Na base do fenômeno da "diáspora africana" tem se desenvolvido ao longo de séculos um duplo movimento. Um constitui a nós negros como grupo em que a dimensão de raça extrapola qualquer outra condição. Ou seja, um negro é antes de tudo um negro, com todas as conotações de subordinação que isto implica, em qualquer parte do chamado Novo Mundo, e a despeito do variado vocabulário utilizado para denominar os descendentes de africanos. 0 outro tem a ver com o fito de que o racismo anti-negro, estabelecido globalmente, nos permite incorporar experiências que dizem respeito não apenas 
a nossa realidade mais imediata, mas também a de outros negros, mesmo que nunca as tenhamos vivenciado diretamente. (BAIRROS, 2017, p. 173).

Ou seja, a formulação de uma rede transnacional de mulheres negras, fundada numa perspectiva de solidariedade, reconhecimento e empatia se dá a partir da percepção que as experiências e vivências do ser negra podem ser compartilhadas e fomentadoras de estratégias conjuntas no que pesem as diferenças subjetivas porque as dimensões do racismo se expressam de forma global. A construção de agendas conjuntas de combate ao racismo e ao sexismo entre mulheres negras se funda, na perspectiva de Keisha Khan Perry, numa luta contínua que se dá também contra o apagamento das memórias e articulações das mulheres negras do histórico de resistência da negritude. Segundo a autora, esse apagamento é um dos aspectos da exploração do patriarcado e da violência da produção de conhecimento, onde mulheres negras são invisíveis, e, na perspectiva do ativismo masculino do movimento negro, as críticas antissexistas das mulheres negras são ignoradas e percebidas como uma traição à negritude.

Ainda que existentes essas limitações, as mulheres negras constituem uma forte rede de resistência aos processos de violência na qual estão imbricadas, é cada vez maior o reconhecimento por parte do ativismo intelectual negro localizado no norte global, da importância das mulheres negras latinas na construção do pensamento feminista negra.

Em palestra recente, proferida na Universidade Federal da Bahia, Ângela Davis, um dos mais proeminentes nomes no pensamento político feminista negro internacional, manifestou como o movimento de mulheres negras no Brasil tem sido central na resistência à exploração capitalista. Esse movimento, de mulheres negras localizadas no norte global, centro econômico e político do poder, às contribuições das mulheres negras latinas enseja o questionamento proposto neste artigo, que é a possibilidade da formulação de redes de conhecimento e trocas entre mulheres que são distintas em termos de raça, mas que compartilham as demandas por equidade de gênero.

Nossa hipótese é que a partir da troca de vivências, experiências e conhecimentos entre mulheres negras e não negras, particularmente nas redes sociais, cria-se a possibilidade da construção de um feminismo dialógico no qual não apenas se reconheça o histórico de apagamento e silenciamento das mulheres negras, mas também que, ao operar esse reconhecimento, se reconfigure o feminismo contemporâneo na direção de ativismos cuja lente da interseccionalidade seja utilizada para além das análises rasas sobre o sofrimento de mulheres negras, visando o protagonismo das elaborações em que as demandas históricas dessas mulheres sejam finalmente colocadas como fundamentais para o superação das inequidades sexuais.

\section{CONSIDERACÕ̃ES FINAIS}

Espaços feministas online, especialmente grupos, lugares relativamente seguros nos quais mulheres podem expor e trocar ideias, podem servir como metáfora para as redes de partilha que auxiliam na construção das teias de saberes. Observar outros aspectos da interseccionalidade é importante para que ela possa operar também como um escopo de formulação de conhecimento. A perspectiva da interseccionalidade para além da padronização do conceito, articulando o mesmo a partir de uma visão crítica que compreenda raça, classe, gênero, sexualidade, etnicidade, nação e exercício da cidadania não operam de maneira única, mas sim a partir de uma lógica que constrói essas intersecções como um fenômeno que implica em inequidades sociais e desumanização de determinados corpos em contextos pré-estabelecidos.

Contudo, o lugar de privilégios simbólicos ocupados pela branquitude precisa ser visualizado e problematizado pelas próprias mulheres brancas. As possibilidades de articulação de um feminismo dialógico, que se dê a partir das redes sociais e que delas se expanda, necessita de uma ruptura contundente da estrutura de poder, o que não implica em uma substituição dos lugares das mulheres negras e brancas dentro dessa 
lógica, mas sim com uma subversão da mesma. Conforme Maria Aparecida Bento, os impactos do racismo no cotidiano das mulheres negras não são visualizados de maneira real, há um ocultamento dos significados da exploração racial na estruturação da sociedade.

Ainda que as inequidades sociais oriundas do racismo sejam facilmente perceptíveis e estimadas em números a partir de uma série de documentos estatais e não-governamentais, elas são aceitas pela branquitude a partir de uma anuência que se manifesta no silêncio e na falta de engajamento efetivo na alteração do panorama social de violências, pobreza, insuficiência de acesso aos recursos sociais para a população negra. Da mesma forma, o não reconhecimento por parte das mulheres brancas dos privilégios sociais e econômicos que acessam em razão da não racialização de seus corpos, acaba por constituir uma antiescuta que inviabiliza a construção de uma rede feminista de partilha de saberes que opere ausente da hierarquização sócio racial.

A observação das interações entre mulheres negras e não negras nos grupos que se organizam no Facebook, nos permitiu perceber de maneira concreta como que a articulação dos discursos de mulheres brancas feministas consiste numa característica da branquitude crítica, que é capaz de reconhecer a existência do racismo, mas não é capaz de se compreender como alguém propenso a silenciar, invisibilizar e ignorar as contribuições, vivências e experiências das mulheres negras sobre aspectos fundamentais das suas próprias vidas. As interações, no que pese a existência de diálogos que se dão a partir de uma crença de alteridade e reconhecimento do outro, acabam sendo maculadas pela presença de uma relativização e de um permanente questionamento sobre a veracidade do que as mulheres negras relatam.

Nesse sentido, também consideramos que a ferramenta do mestre não é a rede social e suas possibilidades, a ferramenta do mestre é a forma com que as linguagens e as interações entre pessoas negras e não negras ainda estão organizadas a partir de uma lógica de dominação e supremacia, que apesar de não aparentar, permanece existente na maneira com que os questionamentos e interações são propostos para as mulheres negras. A existência de uma ideia muito bem articulada de que pessoas em condições de opressão são responsáveis pela educação e reconstrução do pensamento do opressor.

Mulheres brancas, também são atingidas por essa lógica, ao serem demandadas da educação de homens para eliminação do sexismo, por exemplo. Contudo, mesmo que elas tenham consciência do que significa isso em termos simbólicos, objetivos e subjetivos, lançam mão da mesma estratégia ao interpelarem mulheres negras sobre a existência ou não de práticas racistas no cotidiano social.

\section{REFERÊNCIAS}

AZEVEDO, Debora et al. A Joanna sou eu, mas a casa é nossa: a emergência de um locus midiático colaborativo feminista. Revista Café com Sociologia, v. 5 , n. 2, p. 64-77, 2016.

\section{BARRETO, Raquel de Andrade. Enegrecendo o}

feminismo 'ou' Ffeminizando a faça: narrativas de libertação em Angela Davis e Lélia González. 2005. 128f. Dissertação (Mestrado em História) - Pontifícia Universidade Católica do Rio de Janeiro, Rio de Janeiro, 2005.

BENTO, Maria Aparecida Silva. Branqueamento e branquitude no Brasil. In: CARONE, Iray; BENTO, Maria Aparecida Silva (org.). Psicologia social do racismo: estudos sobre branquitude e branqueamento no Brasil. Petrópolis: Vozes, 2002.

CALDWELL, Kia Lilly. Fronteiras da diferença: raça e mulher no Brasil. Estudos Feministas, Florianópolis, v. 8, n. 2, p. 91, 2000.

CARDOSO, Lourenço. Branquitude acrítica e crítica: A supremacia racial e o branco anti-racista. Revista Latinoamericana de ciencias sociales, niñez y juventud. v. 8, p. 607-630, 2010 
CARVALHO, Mário Felipe de Lima. Nossa esperança é ciborgue? Subalternidade, reconhecimento e "tretas" na internet. Revista Estudos Feministas, Florianópolis, v. 25, n. 1, p. 347-363, 2017.

COLLINS, Patricia Hill. Black feminist thought: Knowledge, consciousness, and the politics of empowerment. New York: Routledge, 2002.

COLLINS, Patricia Hill. Intersectionality's definitional dilemmas. Annual Review of Sociology, v. 41, p. 1-20, 2015.

COLLINS, Patricia Hill. Learning from the outsider within: The sociological significance of Black feminist thought. Social problems, v. 33, n. 6, p. 14-32, 1986.

CRENSHAW, Kimberlé. Documento para o encontro de especialistas em aspectos da discriminação racial relativos ao gênero. Estudos Feministas, Florianópolis, v. 10, n. 1, p. 171-188, 2002.

CRENSHAW, Kimberlé. Mapping the margins: intersectionality, identity politics, and violence against women of color. In: FINEMAN, Martha Albertson; MYKITIUK, Rixanne (ed.), The public nature of private violence. Nova York: Routledge, $p$. 93-118, 1994

GONZALES, Lélia. Racismo e sexismo na cultura brasileira. Ciências Sociais Hoje, Brasília, ANPOCS, p. 223-244, 1983.

HARRIS, Angela P. Critical Race Theory. In: BALTES, Paul B.; SMELSER, Neil J (ed.). International Encyclopedia of the Social \& Behavioral Sciences. Amsterdam: Elsevier, 2012. Disponível em: http://works.bepress.com/angela_ harris/17. Acesso em: 16 jul. 2017

HOOKS, Bell. Aint' I a woman: Black women and feminism. Boston: South End Press, 1981

LORDE, Audre. Sister Outsider. New York: The Crossing Press,1984

PERRY, Keisha-Khan. The Groundings with my sisters: Toward a black diasporic feminist agenda in the Americas. The Scholar and Feminist Online, v. 7, n. 2, 2009. 
